AN INTERNATIONAL JOURNAL

\title{
Horizontal Transmission and Effect of the Temperature in Pathogenicity of Beauveria bassiana Against Diatraea saccharalis (Lepidoptera: Crambidae)
}

\author{
Virgínia Michelle Svedese ${ }^{1 *}$, Elza Áurea de Luna Alves Lima ${ }^{1}$ and Ana Lúcia Figueiredo \\ Porto $^{2}$ \\ ${ }^{1}$ Departamento de Micologia; Universidade Federal de Pernambuco. ${ }^{2}$ Departamento de Morfologia e Fisiologia \\ Animal; Universidade Federal Rural de Pernambuco; Recife - PE - Brasil
}

\begin{abstract}
The aim of this work was to evaluate the effect of temperature on the pathogenicity of Beauveria bassiana against Diatraea saccharalis and evaluate the horizontal transmission capacity among the sugarcane borer larvae. The strains were most pathogenic at $26^{\circ} \mathrm{C}$, followed by $32^{\circ} \mathrm{C}$ than at $20^{\circ} \mathrm{C}$, with respective mortalities of 100,50 and $30.3 \%$. The lethal time was also affected by the temperature, with the shortest $L T_{50}$ observed at $26^{\circ} \mathrm{C}(2.2$ days) and the longest at $20^{\circ} \mathrm{C}$ (16.2 days). The URM2915 strain appeared most effective in all the experiments as having potential for deployment in biological control programs for the sugarcane borer. Results in horizontal transmission of $\mathrm{B}$. bassiana showed that this procedure could also be adopted as control strategy for the sugarcane borer.
\end{abstract}

Key words: Sugarcane borer, Lepidoptera, entomopathogenic fungus, biological control, autodissemination

\section{INTRODUCTION}

Brazil is the largest sugarcane producer in the world, followed by India and China. With over seven million hectares planted and a production of over 480 million tons, the country is world leader in the technology for the production of ethanol. This advantage stems from the suitability of sugarcane for planting in the regions of tropical climate, hot and moist, with prevailing temperature between 19 and $32^{\circ} \mathrm{C}$ and well distributed rainfall patterns, with aggregate rates of over 1000 millimeters a year. However, below $20^{\circ} \mathrm{C}$, or above $35^{\circ} \mathrm{C}$, growth rates become very slow and above $38^{\circ} \mathrm{C}$, it is virtually null (EMBRAPA 2011).
The sugarcane borer, Diatraea saccharalis Fabricius (Lepidoptera: Crambidae), is considered one of the most harmful pest for sugarcane farming, not just in Brazil, but also in the majority of the countries where this crop is farmed. The borer acts in the internodes of the sugarcane stalk, digging galleries, which later allow other diseases to become established, resulting in reduced sugar production and in fermentation which is responsible for the production of alcohol (Gallo 2002). Given the cryptic habit, the conventional control measures using chemical pesticides targeted at the larvae are practically useless (Cruz 2007). Therefore, the use of natural agents, such as entomopathogenic fungi, appears as an excellent form of control alternative (Azevedo 1998). The entomopathogenic fungus Beauveria bassiana

*Author for correspondence: vsvedese@ hotmail.com 
(Balsamo) Vuillemin is of generalized occurrence in all these countries, being the most frequently found on insect and soil samples, where they are able to subsist for long periods of time (Alves 1998; Lacey et al. 2001).

As reported by Alves and Lecuona (1998), the simple presence of a structure of the pathogen on an insect, or in it, is not condition sufficient for the onset of a disease; several factors (biotic and abiotic) are involved in promoting the occurrence of infection. Among the several environmental factors that affect pathogenic insects, temperature, moisture and solar radiation are probably the most severe (Inglis et al. 1996). Nonetheless, any strategy for the deployment of $B$. bassiana in the field as a myco-insecticide needs to take into account the prevalent weather conditions in the target areas (Luz and Fargues 1997). For this purpose, some studies have simulated different environmental situations and assessed the virulence of entomopathogenic fungi (Tefera and Pringle 2003; Dimbi et al. 2004; Bouamama et al. 2010).

Another important aspect in the biological control is the pathogen's transmission capacity between the different hosts, since the viability of horizontal transmission represents a new opportunity for Integrated Pest Management programs (Toledo et al. 2007) and offers a few advantages such as reduction in both, the volume of inoculum and of the area treated with the fungus, minimizing the adverse effects in non-target organisms (QuesadaMoraga et al. 2008). The horizontal transmission between different hosts of $B$. bassiana (GarcíaMunguia et al. 2011), Metarhizium anisopliae (Metsch.) Sorokin (Peng et al. 2011) and Isaria fumosorosea (= Paecilomyces fumosoroseus) (Wize) Brawn \& Smith (Avery et al. 2010) has already been shown. However this is first attempt at assessing the transmission of $B$. bassiana between the larvae of $D$. saccharalis.

Based on the ideal development temperatures for sugarcane plantation, this work aimed to determine in laboratory, the effect of different temperatures on the efficiency of $B$. bassiana to control the sugarcane borer, as well as evaluate the fungi's transmission capacity between the individuals of D. saccharalis, with a view to providing inputs for defining new biological control strategies for this pest.

\section{MATERIALS AND METHODS}

\section{Diatraea saccharalis larvae}

The third stage borers were obtained from the Sugarcane Experimental Station of Carpina/ Pernambuco/Brazil and maintained on a Hensley and Hammond (1968) modified artificial diet, consisting basically in a solution of vitamins, Wesson salts, sugar, soy meal, wheat germ, ascorbic acid and water. However, $24 \mathrm{~h}$ before the bioassays, each larva was confined individually in transparent containers $(17 \mathrm{~cm} \times 21 \mathrm{~cm} \times 25 \mathrm{~cm})$ with sugarcane stalks (as a food source).

\section{Fungal Strains}

The $B$. bassiana isolates URM2915 (isolated from Nezara viridula Hemiptera: Pentatomidae in Paraná, BR) and URM3447 (isolated from Castnia licus Lepidoptera: Castniidae in Pernambuco, BR) was supplied by Micoteca URM (University Recife Micology /UFPE). The fungus was inoculated in Petri dishes containing potatoes dextrose agar + chloramphenicol (0.05\%), supplemented with $0.5 \%$ of yeast extract (PDAY) and incubated at $26^{\circ} \mathrm{C}$ for 12 days for conidiation. Following this, conidia suspension was prepared in $0.01 \%(\mathrm{v} / \mathrm{v})$ Tween-80 in distilled water and sprayed through the use of a 35-ml glass atomizer on ten D. saccharalis larvae placed on Petri dishes and incubated at $26^{\circ} \mathrm{C}$ until insect death. Newly emerged conidia from the insect were subcultured not more than four times at ten days intervals in PDA and used to prepare the reactivated inoculum suspension containing $10^{8}$ conidia/mL (Ito et al. 2007). To confirm the viability, the conidia were spread on PDAY and incubated at $26^{\circ} \mathrm{C}$ for $16 \mathrm{~h}$. Germination rates were scored at $400 \times$ magnification by observing at random 100 conidia for the presence of germ tubes. Germination was at least $90 \%$ throughout the study.

\section{Effect of Temperature on Pathogenicity of the Beauveria bassiana Against Diatraea saccharalis}

Ten larvae were immersed in $3.0 \mathrm{ml}$ of the reactivated inoculum suspension for 30 seconds in a Petri dish. Later, they were individualized in the containers with sugarcane stalks as nutrition substrate and maintained at 20,26 and $32^{\circ} \mathrm{C}$. Five replicates were conducted at each temperature. As a control, ten larvae were immersed for 30 seconds in with sterile water containing $100 \mu$ of Tween80. Mortality was recorded daily for seven days. 
Dead insects were placed on moistened filter paper-lined Petri dishes and incubated at their temperatures and $80 \%$ relative humidity. Dead larvae were removed daily, immediately surface sterilized with $1 \%$ sodium hypoclorite followed by three rinses with sterile distilled water, placed on sterile wet filter paper in sterile petri dishes. Mortality due the fungus was confirmed by the microscopic examination of hyphae and spores on the surface of the cadaver (Dimbi et al. 2004).

\section{Horizontal Transmission of Beauveria bassiana Between Diatraea saccharalis Larvae}

After being inoculated following the same experimental protocol described above, five larvae cadavers were then carefully transferred to Petri dishes $(150 \times 15 \mathrm{~mm})$ and clean larvae were introduced at three proportions: 1:1 (5 cadavers and 5 clean larvae), 1:2 (5 cadavers and 10 clean larvae) and 1:3 (5 cadavers and 15 clean larvae). The control consisted of 20 clean larvae. Each proportion was replicated four times, and the whole experiment was repeated 90 days later with insects from a new generation and new conidial plates (Quesada-Moraga et al. 2008).

The bioassay was conducted at $26^{\circ} \mathrm{C}$ and the mortality was monitored for seven days. Dead larvae were removed daily, immediately surface sterilized with $1 \%$ sodium hypoclorite followed by three rinses with sterile distilled water, placed on sterile wet filter paper in sterile Petri dishes. Mortality due the fungus was confirmed by the microscopic examination of hyphae and spores on the surface of the cadaver.

\section{Statistical Analysis}

Statistical significance among the treatments was determined using a one-way ANOVA and mean separation were compared using the Tukey's test $(\mathrm{P}<0.05)$ with software for statistical analysis (SPSS 2003). Lethal time $\left(\mathrm{LT}_{50}\right)$ values for insect mortality were determined by a Probit analysis.

\section{RESULTS AND DISCUSSION}

B. bassiana was pathogenic for the sugarcane borer; however, the different test temperatures had a significant effect on the mortality $(d f=2$; $F=1040.08 ; \mathrm{p}<0.01)$ and differed among the strains $(d f=1 ; F=54.0509 ; \mathrm{p}<0.01)$. There was a significant level of interaction between the temperatures and strains $(d f=4 ; F=73.2821$; $\mathrm{p}<0.01$ ) (Fig. 1). Mortality in the control group was low, not exceeding $8 \%$ at any of the temperatures. As has been emphasized by several authors, any strategy for the deployment of this fungus on the field, as a myco-insecticide must necessarily take into account the prevalent climate conditions at the target areas (Luz and Fargues 1997; Ekesi et al. 1999; Bouamama et al. 2010). So, the selection of strains tolerant to the ideal crop development and production temperature for the plant of interest is necessary for pathogens to be used successfully in the biological control programs.

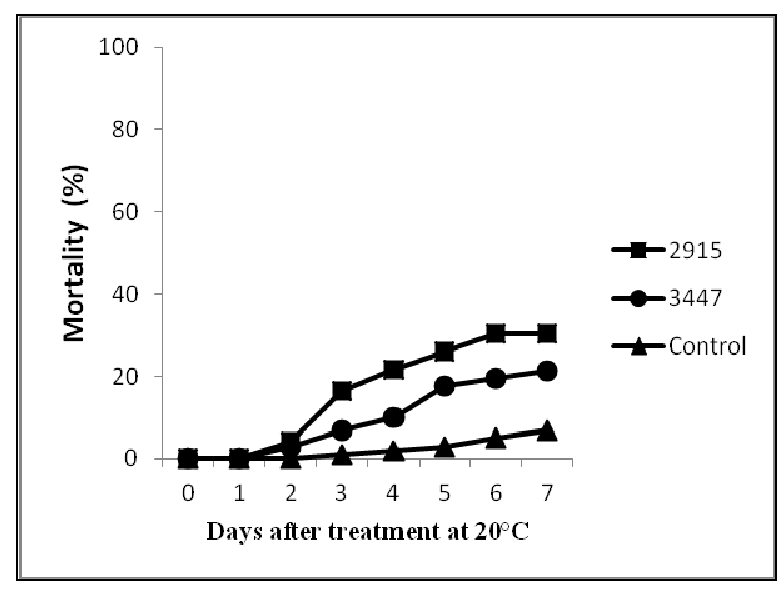



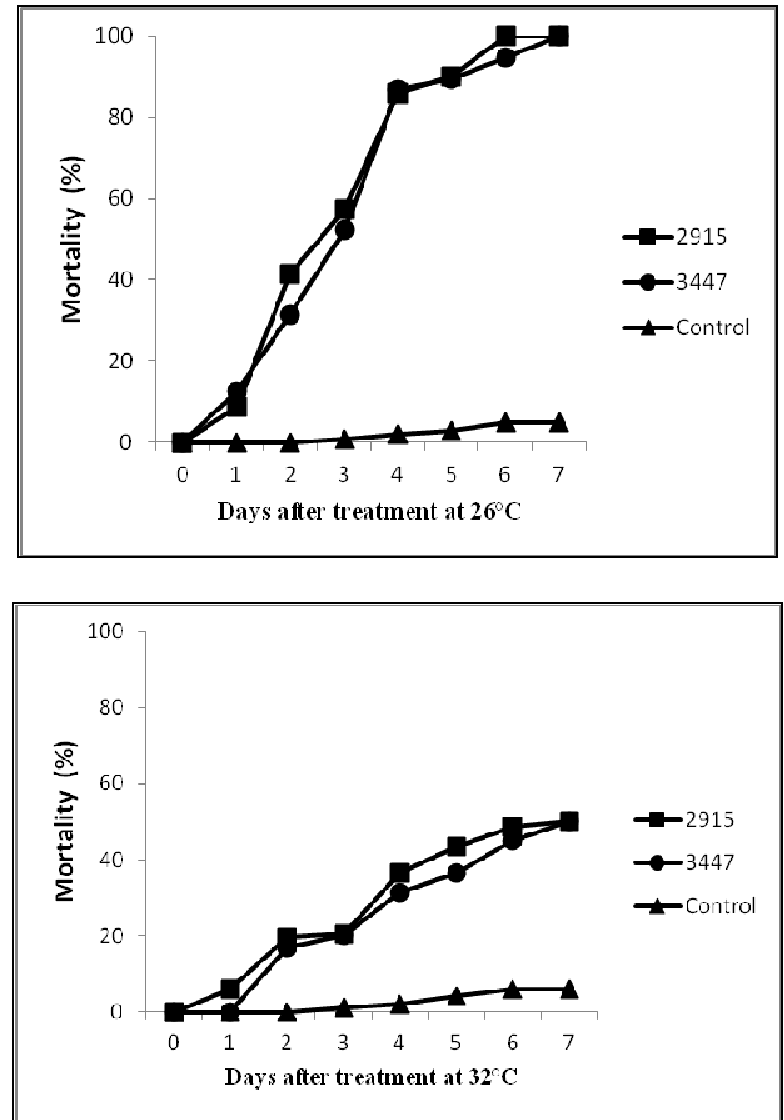

Figure 1 - Mortality (\%) of Diatraea saccharalis larvae inoculated with Beauveria bassiana (URM 2915 and URM3447) under different temperatures.

Although the strains were pathogenic at all the test temperatures, the effect on pathogenicity of $B$. bassiana against $D$. saccharalis was also high. The strains were more pathogenic at 26 and $32^{\circ} \mathrm{C}$ than at $20^{\circ} \mathrm{C}$ (Fig. 1). For example, at the end of the experiment at $20^{\circ} \mathrm{C}, \mathrm{B}$. bassiana URM 2915 caused a mortality of $30.3 \%$, whereas the mortality caused at 26 and $32^{\circ} \mathrm{C}$ was of 100 and $50 \%$, respectively. B. bassiana URM2915 showed mortality superior to URM3447 only at $20^{\circ} \mathrm{C}$. Similar results have been reported earlier using this entomopathogen against other insects (Sun et al. 2003; Dimbi et al. 2004; Brooks et al. 2004). The highest mortality $(100 \%)$ displayed by both the strains was at $26^{\circ} \mathrm{C}$, which was in agreement with the experiments of Alexandre et al. (2008), where mortality of the Alphitobius diaperinus Panzer (Coleoptera: Tenebrionidae) larvae caused by $M$. anisopliae and B. bassiana at $26^{\circ} \mathrm{C}$, was of 93.3 and de $95.5 \%$, respectively. When these fungi were incubated at $32^{\circ} \mathrm{C}$, larval mortality was $68.9 \%$ for $M$. anisopliae and $28.9 \%$ for B. bassiana. Differences in the mortality could be explained by the fungi's biological characteristics. According to Hallsworth and Magan (1999), excellent growth rates could be obtained for $\mathrm{B}$. bassiana at $25^{\circ} \mathrm{C}$; however, this fungus featured good growth at the 20 to $30^{\circ} \mathrm{C}$ range. When exposed to higher temperatures, such as for example, at $37^{\circ} \mathrm{C}$, growth was nearly nil. However, better tolerance to higher, or lower temperatures could be related to the climate origin region of the isolate, as shown by Imoulan et al. (2011) on analyzing the occurrence, thermotolerance and virulence of $B$. bassiana isolates to Ceratitis capita Wiedemann. Ment et al. (2010) have shown the influence of environmental conditions on the development of $M$. anisopliae on the tick Rhipicephalus annulatus and reported for the first time the occurrence of chlamydospores as unit of infection at high temperatures, instead of conidia. Therefore, it was clear that fungi have different strategies to survive the adverse 
conditions and these characteristics could become fundamental in establishing the disease.

Through Probit analysis, the Lethal Time, occurring as a function of the different temperatures was obtained (Table 1). The $\mathrm{LT}_{50}$ was also significantly affected by the temperature $(F=176.36 ; \mathrm{p}<0.01)$. The lowest $\mathrm{LT}_{50}$ was seen at $26^{\circ} \mathrm{C}$ for both the strains. Based on the overlap of the confidence intervals, there was a significant difference between the $\mathrm{LT}_{50}$ of both the strains when the larvae were subjected to 20 and $26^{\circ} \mathrm{C}$. Although there was not very much difference at $32^{\circ} \mathrm{C}$, the $\mathrm{LT}_{50}$ for URM2915 was slightly shorter, reaching 6.56 days, while the one for URM3447 it was 6.81 days.

Table 1 - Median Lethal Time $\left(\mathrm{LT}_{50}\right)$ of Beauveria bassiana against Diatraea saccharalis at different temperatures

\begin{tabular}{ccccc}
\hline Temperatures & Strains & LT $_{\mathbf{5 0}}(\mathbf{C I})^{\mathbf{1}}$ & Slope & $\boldsymbol{\chi 2}^{\mathbf{2}}$ \\
\hline \multirow{2}{*}{$20^{\circ} \mathrm{C}$} & URM2915 & $11.08(8.61-18.05)$ & $2.05 \pm 0.35$ & 2.47 \\
& URM3447 & $16.26(11.13-38.81)$ & $2.00 \pm 0.41$ & 1.54 \\
\hline \multirow{2}{*}{$26^{\circ} \mathrm{C}$} & URM2915 & $2.29(2.11-2.47)$ & $3.81 \pm 0.24$ & 5.07 \\
& URM3447 & $2.51(2.32-2.70)$ & $3.94 \pm 0.25$ & 9.80 \\
\hline \multirow{2}{*}{$32^{\circ} \mathrm{C}$} & URM2915 & $6.56(5.64-8.07)$ & $1.87 \pm 0.22$ & 3.45 \\
& URM3447 & $6.81(5.85-8.69)$ & $1.98 \pm 0.30$ & 2.44 \\
\hline
\end{tabular}

${ }^{1}$ Confidence interval (Significance at the $95 \%$ ).

Bugeme et al. (2009) assessed the effect of temperature on the pathogenicity of $B$. bassiana (isolated from Africa) on spider mite Tetranychus urticae Koch and noted that the $\mathrm{LT}_{50}$ decreased as the temperature increased, being 9.8 days at $20^{\circ} \mathrm{C}$, 4.9 at $25^{\circ} \mathrm{C}$ and 3.3 at $32^{\circ} \mathrm{C}$. As reported by Lohmeyer and Miller (2006), differences between the $\mathrm{LT}_{50}$ was a tool often used in selecting the strains, which was interesting given that, in addition to being virulent, the fungus quickly killed its hosts. This put B. bassiana URM2915 at an advantage over URM3447, since the borers treated with this strain died more quickly than the ones treated with the other strain.

Different from other insect pathogens, entomopathogenic fungi can infect their hosts by contact, penetrating the insect's cuticle, through horizontal transmission (Quesada-Moraga et al. 2004). The present results obtained in the experiments with the B. bassiana URM2915 and Beauveria bassiana URM3447 strains showed that there was efficient transmission between the individuals of $D$. saccharalis, with mortality rates varying between 59 and $95.5 \%$ (Table 2). These results were the first report on the transmission of B. bassiana between the cadavers and healthy larvae of $D$. saccharalis. Hence, cadavers of the borers in the stalks could contribute in the future for the dissemination of the disease in the plant. This feature could be extremely important in controlling the sugarcane borer using fungi, since the better part of this insect's lifecycle takes place inside the stalks making it harder for direct applications to reach the pest. Talaei-Hassanloui et al. (2009) have shown that B. bassiana transferred between the adults of Eurygaster integriceps Puton, causing mortalities of 50 to $65 \%$. Dembillio et al. (2010) also reported that B. bassiana was transmitted between the adult coleopterans of palm trees and Rhynchophorus ferrugineus Olivier and their effects were also seen in the following generation.

Table 2 - Horizontal transmission of Beauveria bassiana from inoculated Diatraea saccharalis larvae to clean larvae at different proportions.

\begin{tabular}{ccc}
\hline \multirow{2}{*}{ Proportion (cadavers/clean) } & MRM2915 & Mortality (\%) \\
\cline { 2 - 3 } & $96.5 \pm 2.1 \mathrm{Aa}$ & URM3447 \\
\hline $1: 1(5 / 5)$ & $95 \pm 1.5 \mathrm{Aa}$ & $85 \pm 2.4 \mathrm{Ab}$ \\
$1: 2(5 / 10)$ & $82 \pm 3 \mathrm{Ba}$ & $80 \pm 2.3 \mathrm{Bb}$ \\
$1: 3(5 / 15)$ & $4.2 \pm 1.2 \mathrm{Ca}$ & $59 \pm 4.4 \mathrm{Cb}$ \\
Control group & $4.2 \pm 0.25 \mathrm{Da}$ \\
\hline
\end{tabular}

Level of significance was determined using Tukey's methods of mean separation where $\mathrm{P}<0.05$. Mean followed by the same letter, small the row and capital letter the line, are not significantly different. 
The efficiency of horizontal transmission depends on a number of parameters, including the number and distribution of individuals in the infected population (Avery et al. (2010). Results showed there was no difference in the mortality caused by B. bassiana URM2915 when the ratios were 1:1 and 1:2. However, when the ratio of healthy individuals with respect to the number of cadavers increased, the mortality dropped off. This was more clearly noted in the treatment with URM3447, in which the mortality varied significantly according to the ratio and fell to $26 \%$ when the ratio was 1:3 (Table 2). In lab experiments, $B$. bassiana conidia were transferred between the treated and untreated adult beetles of Ips typographus L., resulting to $96 \%$ mortality when the ratio was of $1: 1$ and $83 \%$ when it was $1: 5$ (Kreutz et al. 2004). Quesada-Moraga et al. (2008) investigated if the adults of $C$. capita infected with $M$. anisopliae transmitted the fungus to uninfected flies of the opposite sex during copula. In addition, the transmission was directly related to the ratio and sex involved.

The capacity of transmission of $B$. bassiana between the borers is an important parameter in selecting a control strategy for this pest, given that the presence of cadavers with the fungus on the field can help in establishing the secondary foci of the disease and, in this way, increase the mortality of the sugarcane borer, in addition to being fundamental in maintaining the inoculum in the environment (Bustilho et al. 2002; Estrada et al. 2004). These results showed that the temperature interfered in the pathogenicity of $B$. bassiana URM2915 and URM3447 against $D$. saccharalis and the fungus could be transmitted between the individuals of the borer, causing significant mortality. Success in horizontal transmission of $B$. bassiana was indicative that this procedure could also be adopted as control strategy for the sugarcane borer.

\section{ACKNOWLEDGMENTS}

The authors thank to Conselho Nacional de Desenvolvimento Científico e Tecnológico (CNPq) for financial support.

\section{REFERENCES}

Alexandre TM, Neves PMOJ, Santoro PH, Alves LFA. Controle associado de Alphitobius diaperinus com o fungo entomopatogênico Beauveria bassiana e inseticidas químicos. Arq Inst Biol. 2008; 75: 481489.

Alves SB. Fungos entomopatogênicos, In Alves SB, editor. Controle microbiano de insetos. Piracicaba: FEALQ; 1998. p. 289- 381.

Alves SB, Lecuona RE. Epizootiologia aplicada ao controle microbiano de insetos. In: Alves SB, editor. Controle microbiano de insetos. Piracicaba: FEALQ; 1998. p. 97-170.

Avery P, Queeley G, Faull J, Simmonds M. Effect of photoperiod and host distribution on the horizontal transmission of Isaria fumosorosea (Hypocreales: Cordycipitaceae) in greenhouse whitefly assessed using a novel model bioassay. Biocont Sci Technol. 2010; 20: 1097-1111.

Azevedo JL. Controle Microbiano de insetos-pragas e seu melhoramento genético. In Melo IS, Azevedo, JL. (Eds.). Controle Biológico. Jaguariúna: Embrapa; 1998. p. 69-96

Bouamama N., Vidal C, Fargues J. Effects of fluctuating moisture and temperature regimes on the persistence of quiescent conidia of Isaria fumosorosea. J Invertebr Pathol. 2010; 105: 139-44.

Brooks AJ, Muro MA De, Burree E, Moore D, Taylor MA, Wall R. Growth and pathogenicity of isolates of the fungus Metarhizium anisopliae against the parasitic mite, Psoroptes ovis: effects of temperature and formulation. Pest Manag Sci. 2004; 60:10431049.

Bugeme DM, Knapp M, Boga HI, Wanjoya AK, Maniania NK. Influence of Temperature on Virulence of Fungal Isolates of Metarhizium anisopliae and Beauveria bassiana to the Two-Spotted Spider Mite Tetranychus urticae. Mycophatol. 2009; 167: 221227.

Bustillo AE, Cárdenas R, Posada FJ. Natural enemies and competitors of Hypothenemus hampei (Ferrari) (Coleoptera: Scolytidae) in Colombia. Neotrop Entomol. 2002; 31: 35-639.

Cruz I. A Broca da Cana-de-Açúcar, Diatraea saccharalis, em Milho, no Brasil. EMBRAPACNPMS, Circular técnica. 2007; 90: 12.

Dembillio O, Quesada-Moraga E, Santiago-Álvarez C, Jaca JA. Potential of an indigenous strain of the entomopathogenic fungus Beauveria bassiana as a biological control agent against the Red Palm Weevil, Rhynchophorus ferrugineus. J Invertebr Pathol. 2010; 104: 214-221.

Dimbi S, Maniania NK, Lux SA, Mueke JM. Effect of constant temperatures on germination, radial growth and virulence of Metarhizium anisopliae to three species of African tephritid fruit flies. BioControl. 2004; 49: 83-94. 
Ekesi S, Maniania, KN, Ampong-nyarko K. Effect of temperature on germation, radial growth and virulence of Metarhizium anisopliae and Beauveria bassiana on Megalurothrips sjostedti. Biocont Sci Technol. 1999; 9: 177-185.

Embrapa Cana-de-açúcar. Brasília. Available from: http://www.agencia.cnptia.embrapa.br/gestor/canade-acucar/Abertura.html

Estrada ME, Romero M, Rivero MJ, Barroso F. Presencia natural de Beauveria bassiana (Bals.) Vuill. en el cultivo de la caña de azúcar (Saccharum sp. híbrido) en Cuba. Rev Iberoam Micol. 2004; 21 : 42-43.

Gallo D, Nakano O, Silveira Neto S, Carvalho RP, Baptista GC, Berti Filho E, et al. Entomologia agrícola. Piracicaba: FEALQ; 2002.

García-Munguía AM, Garza-Hernández JA, RebollarTellez EA, Rodríguez-Pérez MA, Reyes-Villanueva F. Transmission of Beauveria bassiana from male to female Aedes aegypti mosquitoes. Parasit Vectors. 2011; 4:24-29.

Hallsworth JE, Magan N. Water and temperature relations of growth of the entomogenous fungi Beauveria bassiana, Metarhizium anisopliae, and Paecilomyces farinosus. J Invertebr Pathol. 1999; 74: 261-266.

Hensley SD, Hammond AH. Laboratory techniques for rearing the sugarcane borer on an artificial diet. $J$ Econ Entomol. 1968; 61: 1742-1743.

Imoulan A, Alaoui A, Meziane AE. Natural occurrence of soil-borne entomopathogenic fungi in the Moroccan Endemic forest of Argania spinosa and their pathogenicity to Ceratitis capitata. World $J$ Microb Biot. 2011; 27:2619-2628

Inglis GD, Johnson DL, Goettel MS. Effects of temperature and thermoregulation on mycosis by Beauveria bassiana in grasshoppers. Biol Control. 1996; 7: 131-139.

Ito ET, Varéa-Pereira G, Miyagui DT, Pinotti MHP, Neves PMOJ. Production of Extracellular Protease by a Brazilian Strain of Beauveria bassiana Reactivated on Coffee Berry Borer, Hypothenemus hampei. Braz Arch Biol Technol. 2007; 50: 217-223.

Kreutz J, Zimmermann G, Vaupel O. Horizontal Transmission of the Entomopathogenic Fungus Beauveria bassiana among the Spruce Bark Beetle, Ips typographus (Col., Scolytidae) in the Laboratory and under Field Conditions. Biocont Sci Technol. 2004; 14: 837-848.

Lacey LA, Frutos R, Kaya HR, Vail P. Insect Pathogens as Biological Control Agents: Do They Have a Future? Biol Control. 2001; 21: 230-248.

Lohmeyer KH, Miller JA. Pathogenicity of Three Formulations of Entomopathogenic Fungi for Control of Adult Haematobia irritans (Diptera: Muscidae). J Econ Entomol. 2006; 99: 1943-1947.
Luz C, Fargues J. Temperature and moisture requirements for conidial germination of the an isolate of Beauveria bassiana, pathogenic to Rhodnius prolixus. Mycopatholo. 1997; 138: 117125.

Ment D, Gindin G, Glazer I, Perl S, Elad D, Samish M. The effect of temperature and relative humidity on the formation of Metarhizium anisopliae chlamydospores in tick eggs. Fungal Biol. 2010; 114: 49-56.

Peng F, Gardescu S, Hajek AE. Transmission of Metarhizium brunneum conidia between male and female Anoplophora glabripennis adults. BioControl. 2011; 56: 771-780.

Quesada-Moraga E, Santos-Quirós R, Valverde-García P, Santiago-Álvarez C. Virulence, horizontal transmission, and sublethal reproductive effects of Metarhizium anisopliae (anamorphic fungi) on the german cockroach (Blattodea: Blattellidae). $J$ Invertebr Pathol. 2004; 87: 51-58.

Quesada-Moraga E, Martin-Carballo I, Garrido-Jurado I, Santiago-ÁLvarez C. Horizontal transmission of Metarhizium anisopliae among laboratory populations of Ceratitis capitata (Wiedemann) (Diptera: Tephritidae). Biol Control. 2008; 47: 115124.

Sun J, Fuxa JR, Henderson G. Effects of virulence, sporulation, and temperature on Metarhizium anisopliae and Beauveria bassiana laboratory transmission in Coptotermes formosanus. J Invertebr Pathol. 2003; 84: 38-46.

Talaei-Hassanloui R, Kharazi-Pakdel A, Hedjaroude GhA. Transmission possibility of the fungus Beauveria bassiana KCF102 by mating behavior between Sunn pest, Eurygaster integriceps (Hem.: Scutelleridae) adults. J Entomol Soc Iran. 2009; 28: 1-6.

Tefera T, Pringle KL. Effect of exposure method to Beauveria bassiana and conidia concentration on mortality, mycosis, and sporulation in cadavers of Chilo partellus (Lepidoptera: Pyralidae). J Invertebr Pathol. 2003; 84: 90-95.

Toledo J, Campos SE, Flores S, Liedo P, Barrera JF, Villasenor A, Montoya P. Horizontal transmission of Beauveria bassiana in the Mexfly, Anastrepha ludens (Diptera: Tephritidae), under laboratory and fieldcage conditions. J Econ Entomol. 2007; 100: 291297.

Received: January 22, 2012; Revised: March 28, 2013; Accepted: May 06, 2013. 
